\title{
Financial Inclusion through Financial Literacy in India: Issues and Challenges
}

\author{
Satish Kumar and Dr.H.G. Joshi
}

\begin{abstract}
Financial Inclusion becomes the effective objective for the 9th Fiver Year plan in India. The effective sharing of economic benefits among under pre vilaged through financial inclusion is the core of the plan. In order to achieve and make this successful, the effective awareness and access to financial instruments and institutions are important. Central bank of the country, RBI has initiated several programmes to achieve the same. The present paper identified the different approaches and innovative ideas which can be implemented in a day to day life the individual. The attempt the paper is suggest several intiatives to the policy makers to achieve the financial literacy in India
\end{abstract}

Keywords--- Inclusive Growth, Financial Literacy, RBI.

\section{INTRODUCTION}

$\mathrm{T}$ HE globalization and economic liberalization, financial liberalization as part of it, have enforced sea changes in economic landscape of almost every country. The change-drivers like technology, market innovation, new vistas of competitive forces have brought extreme innovations in new product discovery, design (with varying patterns of entry, exit, tenure, risk \& return profiles), delivery, administration etc. and have thrown plethora of such options before the consumers to choose from. In fact, such new options have flooded the traditional Indian financial market with bounty of new products and, sometimes, frightened the consumers with their complex and tricky underlying calculations, models, risk assumptions, objectives etc. Given the fact that traditionally Indian society is rural in nature which is not served by the formal financial institutions to a great extent but by the money-lenders at an exorbitantly high interest rates, there were apprehensions in the in the minds of the consumers regarding the mechanics of the new instruments and their riskreturn profiles. Added to this, such phenomena of the marketplace like predatory pricing, high levels of consumer debt, low savings rate etc. have started posing threats to the consumer well-being. It has become imperative to establish credibility in the consumers regarding the soundness of the financial innovations and their ability to ensure their financial \& social wellbeing.

On the other hand, the effectiveness and success of the monetary \& credit policy and the fiscal policy depends on the stimulation of the consumers to behave in the desired direction. These macro-economic models assume apt

Satish Kumar, Assistant Professor, Department of Commerce, Manipal University, Manipal. Manipal.

Dr.H.G. Joshi, Professor, Department of Commerce, Manipal University, DOI: 10.9756/BIJIEMS.8341 behaviors from the consumers and concentrate on the supplyside corrections and fine-tuning. In the absence of the proper knowledge of the financial environment and its various phenomena like inflation, credit-crunch, economic behaviors, risk-return framework etc. in the minds of the consumers, it will be difficult for them to understand the intent of the policy initiatives and to plan their current \& long-term financial behaviors. This could create a divergence between the planned and actual outcomes and could cause the policy initiatives ineffective.

The above-mentioned facts make it imperative to undertake financial literacy activities as a means to create and enhance the knowledge, attitude, skill and behaviors for all the stakeholders so that the policy objectives and individual financial wellbeing both could be achieved simultaneously, which could ultimately translate into a robust and healthy economy with in country.

\section{DEFINITION}

Financial literacy activities span diverse target entities like regulators, intermediaries, consumers, consumer \& industry associations etc., diverse sectors like banking, securities markets, insurance, retirement planning products etc., diverse levels like basic financial knowledge, sector-focused, productspecific, consumer protection etc., diverse individuals like illiterate, educated, rural, urban, employed, unemployed etc; this makes it difficult to define the term 'financial literacy' in clear-cut terms. The Organization for Economic Co-operation and Development (OECD), Paris, France defines Financial Literacy as "a combination of financial awareness knowledge, skills, attitude and behaviors necessary to make sound financial decisions and ultimately achieve individual financial wellbeing”.

Hence, the financial literacy aims at empowering the stakeholders to play the game by clearly comprehending the rules of the game and to play a safe game for the benefit of all and to safeguard the system as a whole.

\section{NEED \& IMPORT ANCE}

The just concluded financial crisis the world over, particularly that of Sub-Prime Crisis in the US, has brought the imminent need for ensuring financial literacy, in adequate levels, for all-Regulators, Intermediaries and the Consumers to the forefront. In fact, the recent global financial crisis has raised the question whether individuals' lack of financial knowledge led them to take out adjustable rate mortgages (ARMs) or incur credit card debt they could not afford ${ }^{2}$ 
In order to ensure financial stability, financial literacy is identified the world over as one of the key elements besides financial inclusion and consumer protection. In order to ensure percolation of various financial, fiscal \& credit policy initiatives and to achieve the desired results, it is essential that suitable responses are mounted both in the demand \& supply sides to the calls made by the policy initiatives by both the Government and various regulators. While the Regulators could ensure the supply-side bottlenecks with their policy initiatives to contain or promote supply of products \& services, the demand-side responses are largely dependent on various parameters which are directly related to the behaviors of the ultimate consumers i.e. the people of the country who are as diverse in their geographical, cultural, religious, financial \& literacy levels, in a vast country like India. Hence, the financial literacy initiative is identified as a vehicle to take the financial inclusion initiatives to translate into financial stability. International organizations like UNDP, OECD etc. and all national regulators and market intermediaries have started to fill the gap with appropriate strategies.

Similarly, in an attempt to take the social inclusion initiatives, one of the goals of Indian Republic, financial inclusion and financial literacy help immensely in bringing the marginalized (socially, economically, educationally) into the formal systems. 'Financial literacy and education plays a crucial role in financial inclusion, inclusive growth and sustainable prosperity'.

\section{ObJectives of the Research StUdy}

- To understand the concept of financial literacy in India

- To identify efforts and strategies followed by the regulators to achieve financial literacy in India

- To suggest some of the new ideas and strategies to achieve financial literacy.

Research Methodology: The present paper designed with the help of secondary information collated from various sources like RBI, SEBI, IRDA etc. The paper also suggests some of the new and innovative strategies which can be used to achieve financial literacy in India.

\section{TARgET SECTIONS}

The focus of the financial literacy encompasses the whole nation in general and the BPL Poor, middle-income groups, salaries persons, High Net-worth individuals, market players, regulators. Though their requirement is dependent on their present knowledge, skill, access to information, geographical location, level of participation in the formal financial system.

The BPL Poor require such literacy as to know the importance of using organised financial channels for their savings requirements. The middle-income groups require to know about thrift \& various safe investment options. Salaried persons require to know about various long-term savings options. High net worth individuals require adventurous products which offer high risk and high return, the latter being their goal. Market players require to know the workings \& mechanics of the products they design and to align them to the country-context, to design such products which will not distort the market sentiment and consumer wellbeing. Regulators require to know the macro-economic workings thoroughly and various deviant practices by all the participants of the system so that they could come up with suitable corrective measures.

\section{PRESENT EFFORTS}

Government of India, at the instance of the guidance of OECD, has formulated a National Strategy for Financial Education (NSFE) during 2012 detailing the case, importance and various aspects of measures to be taken towards building a sound financially literate country and to create resilient consumers. The NSFE calls for nation-wide coordinated efforts from all the stakeholders to enhance the financial maturity of the citizens and a resulting strong economy with complete financial inclusion and consumer empowerment. The NCFE takes note of the need for financial education, identified policy design requirements, institutional arrangements and extends guidance to various stakeholders to tread forward towards realizing the broad national goals besides prescribing a list of topics for school curriculum. With this, India joins a select list of countries who took concrete steps in putting the national financial literacy efforts on track.

Various Market Regulators have initiated efforts to augment the financial literacy activities in their respective domains in the country as follows, as made out by National Strategy for Financial Education.

Reserve Bank of India has undertaken a project titled "Project Financial Literacy". The project has been designed to be implemented in two modules, one module focusing on the economy, RBI and its activities, and the other module on general banking. The material is created in English and other vernacular languages. It is disseminated to the target audience with the help of banks, local government machinery, schools and colleges through presentations, pamphlets, brochures, films and also through RBI's website.

The Security and Exchanges Board of India (SEBI) has taken initiaves and appointed Certified Resource Persons who organize workshops to the target segments on various aspects viz. savings, investment, financial planning, banking, insurance, retirement planning etc. More than 3500 workshops have been already conducted in various states covering around two lakh and sixty thousand participants. Investor education programs are conducted by SEBI through investor associations all over the country

Insurance Regulatory and Development Authority (IRDA) has taken various initiatives to conduct Awareness programs on television and radio and simple messages about the rights and duties of policyholders, channels available for dispute redressal etc. have been disseminated through television and radio as well as the print media through sustained campaigns in English, Hindi and 11 other Indian languages.

The Pension Fund Regulatory and Development Authority (PFRDA) has developed FAQ on pension related topics on its web, and has been associated with various Non-Government Organizations in India in taking the financial literacy about pension services to the disadvantaged community. 
Commercial banks have initiated various measures for creating awareness through Financial Literacy and Counseling Centers and Rural Self Employment Training Institutes on financial literacy across the length and breadth of the country.

Many Stock Exchanges, Broking Houses and Mutual Funds, NGOs have initiatives in the field of financial education that spawns conducting of seminars, issuance of do's and don'ts, and newspaper campaigns. Insurance companies too, carry out campaigns and other educational activities for generic education in insurance.

\section{STRATEGIES}

All personal consumers are both savers and borrowers in the financial system. Even after two decades of financial liberalization, the percentage of people saving their money in the homes is around $23.4 \%$ which means almost $25 \%$ of the money incomes is not brought into the credit flow multiplier channels. Even there lies a basic confusion among the individual consumers about matching term of the savings to their requirements. Hence, the primary focus of the financial literacy activities is the individual consumer with different income levels.

The requirements of BPL Poor are that of the knowledge about alternative formal avenues of finance to help them get rid of the clutches of the traditional money lenders. In the case of salaried persons, their requirements are mostly related to availing credit and planning for their retirements. In the case of the High Net-worth individuals, their aim is to maximize return on their investments. Since greed for higher returns requires higher risks, for which the risk-return framework has to be properly appraised so as to avoid predicaments out of the imprudence.

For market players, the complete awareness about the basic mechanics i.e. compounding, time value of money, riskreturn frameworks, safety \& security of the investors etc. have to form part of the financial literacy programs so that they could avoid possible scams, frauds and Ponzi schemes being floated which ultimately dishearten the entire efforts of the Government and the Regulators.

For Regulators, the financial literacy entails ensuring proper knowledge to frame such policies which take into consideration entire gamut of the conditions of the consumers, the capability of the system to translate the policy initiative into reality and the working of the macro-economy in realizing broader national objectives.

For delivering the actual content, various ways are possible, which are purely target-population-dependent. As an effective tool, it has been recognized internationally that imbibing the financial literacy concept, spirit \& syllabi into the school curriculum so that the future citizens consider such body of knowledge as homogenous and not as a foreign body to be learnt. Such efforts could also be supplemented by continuing the financial literacy initiative as one of the subjects in all entrance examinations for jobs.
VIII. SOME OF THE EXISTING METHODS FOR INSTRUCTION OF THE FinANCIAL LiTERACY THAT ARE PRESENTLY USED ARE

Social Media: It has emerged as dominant form of communication among the present-day tech-savvy youth and business community. Campaigns on internet websites, facebook, twitter, blog posts, RSS feeds are recognized to have wider reach at a significantly low cost.

Resource Centres: In order to reach the rural community, where a person-to-peson contact gives better results and to undertake long-term measures, establishment of Resource Centres is the viable option.

Adult Education: For adults who did not receive any formal education at optimum levels, it is treated as one of the delivery mechanisms at village levels.

Self Help Groups: One of the viable methods of training the home-makers and rural women, SHG route is one of the promissing channels.

Micro Finance Institutions: They are specialised institutes in rural credit landscape working closely with SHGs, NGOs and Rural Development organisations. They could supplement the activities of all other ground level organisations as resource persons with their professional knowledge.

Mass media: For a country with vast geographical area and with huge diversities (geographical, cultural, religious, economic, ethnical etc.) mass media is the best way to reach the unreachable areas in a cost effective manner.

Associations for various purposes: They will be vested with such roles as to literate the members for better results towards the end.

School Curriculum: As a long-term mechanism, it is widely accepted across the spectrum that including the financial literature into the school curriculum could bring better results towards building financially literate country.

\section{IDEAS FOR NEW STRATEGIES}

Since the task of providing financial literacy is a long term process with heterogenous target audience, it requires approaching the problem through every possible means. The author feels that in addition to some of the existing methods, the following new ideas could also serve as one of the effective strategies that could supplement the present efforts towards universal coverage:

Subject in Competitive Exams: The possibility of including the financial literacy as part of the General Studies / Optional Papers could be considered. This could serve as a compulsory training for the new generation professionals to pre-acquire the required knowledge. Moreover, this could also serve as a milestone to include those who were excluded at school levels by some reason or the other.

Compulsory Prolifiration Commitment: The idea is to commit the public places like Movie theatres, mass media, educational institutions etc. to voluntarily or involuntarily (through regulatory compulsions) take the onus of sharing 
their mite towards prolifiration of financial literacy among their clients through display boards, hoardings, slides, leaflets, advertising on their stationery etc.

Making Mandatory IN Know Your Customer (KYC) Form: It could also be considered as a pre-requisite for the purpose of entering into the financial system. Since KYC details are necessary for such an entry, few ideas to ensure that the prospective entrant voluntarily makes efforts to acquire the knowledge, if they are to possess some sort of pre-requisite knowledge. It is possible when KYC has some data capture fields about the prospective customers' knowledge.

Government Schemes Linkage: All Government schemes, directly financed to individuals or through NGOs, should have compulsory training on Financial Literacy. This could translate the beneficiaries as worthy entrepreneurs.

Prolifiration Through Libraries: It could be considered to allocate some space in the vast network of public, university and other libraries to create a section on financial literacy books. This wing could engage in providing books, charts and other literature; besides, some interactions, workshops, seminars and some promotional measures like essay-writing competitions, debating etc. could also be planned by them.

\section{Conclusion}

Despite intensified, coordinated and cumulative efforts by various Governments, Regulators and market intermediaries, the task of taking financial literacy throughout the length and breadth is not as simple task as it appears theoretically. It requires much more commitment on the parts of all the agencies to leave no stone unturned. Even the civil society should cut across caste, creed, personal preferences etc. to come along voluntarily in supplementing the efforts of all the agencies towards building a financially literate, stable \& robust economy for the present $\&$ future generations.

\section{REFERENCES}

[1] K.C. Chakrabarthy, "The what, why, who and how of financial literacy", Mumbai: Reserve Bank of India, 2013.

[2] M.R. Boucher, "Delivering Financial Literacy: Challenges, Strategies and Instruments”, Bengaluru: RBI-OECD Workshop, 2010.

[3] A. Lusardi and O.S. Mitchell, "The economic importance of financial literacy: Theory and evidence”, Journal of Economic Literature, Vol. 52, No. 1, Pp. 5-44, 2014.

[4] T.S. Vijayan, "Role of Financial Institutions in Financial Education", OECD Conference on Financial Education co-hosted by PFRDA at ITC Mourya Sheraton, Delhi.

[5] India, Govt.of. National Strategy for Financial Education. Mumbai: Reserve Bank of India, 2012.

[6] K.C. Chakrabarthy, "Financial Literacy and Consumer Protection", Washington DC, 22 April 2012.

[7] S. Bose, P. Ghosh and A. Sardana, "Resource requirements for Right to Education (RTE)", Normative and the Real, No. 17/201, 2017.

[8] Jennifer and Robbinson, "The case for financial literacy", Carlton University, 2012. 